\title{
Lower oesophageal web
}

\author{
VIKING OLOV BJÖRK AND CONSTANTIN G. CHARONIS \\ From the Department of Thoracic Surgery, University Hospital, Uppsala, Sweden
}

\begin{abstract}
A patient with a 'congenital' oesophageal web was suffering from dysphagia and was treated surgically. A review is made of a few similar, well-documented cases. An effort is made to compare the clinical and pathological characteristics of the lesion and to discuss its pathogenesis.
\end{abstract}

The purpose of this paper is to present the case of a young adult patient who had suffered since birth from dysphagia. The diagnosis of cardiospasm was made during childhood and the lesion was diagnosed recently, and proved at operation, to be an annular web involving the mucosa and submucosa, situated $3 \mathrm{~cm}$. above the oesophagogastric junction.

An attempt will be made to correlate the clinical picture and radiological and pathological findings of the above well-documented case with others reported in the literature. These patients have usually had similar presenting symptoms, radiographs, and operative findings, but they have had different clinical histories as well as different histological findings. These observations suggest that this lesion may have several pathogeneses (Sweet, 1956 ; Adams, 1956).

Although congenital stenosis of the lower oesophagus has always been considered a rarity (Beatty, 1928 ; Guilleminet, 1947 ; Guilleminet and Lacour, 1947 ; Forssner, 1907 ; Findlay, 1932 ; Malenchini and Resano, 1953), Macmillan (1931, 1935), while reporting the radiological findings in a series of 1,600 patients complaining of dysphagia, found oesophageal webs in $13 \%$ of all cases, excluding those in whom foreign bodies were accounting for the dysphagia.

Since the original report in 1953 of Ingelfinger and Kramer, who first called attention to the significance of a web in the lower oesophagus seen radiologically in cases of dysphagia, many different authors have focused their attention on this subject.

Webs were described by Templeton in 1944 as a ring-like constriction seen only in the distended state of the oesophagus, a few centimetres above the diaphragmatic shadow. Templeton emphasized the importance of distinguishing this from organic stricture. Similar observations were made by
Jutras, Levrier, and Longtin (1949), Johnstone (1951), and Evans (1952).

Ingelfinger and Kramer presented in 1953 six patients, each of whom was suffering from sudden attacks of dysphagia. Radiologically 'the picture of a constriction ring-a ring-like band 2 to 6 $\mathrm{mm}$. in width-representing a sharply localized lesion with clearly defined margins, situated 2.5 to $6 \mathrm{~cm}$. above the junction of the oesophagus and stomach' was found. Only one of their patients was operated upon, and a resection of the lower $4 \mathrm{~cm}$. of the oesophagus was performed.

Schatzki and Gary (1953) reported in the same year similar radiological findings in five adult patients complaining of dysphagia. The diameters of the rings were 3 to $18 \mathrm{~mm}$. and they were tested with barium-filled gelatin capsules. Only one patient was operated upon.

Bugden and Delmonico presented in 1956 two patients who had lower oesophageal webs and who complained of dysphagia 'which seemed to have been related to the obstructive potential of the bolus swallowed'. Both were operated upon. At thoracotomy 'the web was leathery in consistency and pliable. The small lumen in both cases ( 3 and $5 \mathrm{~mm}$. respectively) could barely be felt with the finger-tip. The mucosa above and below the defect felt normal'.

In 1958 MacMahon, Schatzki, and Gary reported a well-documented case that had been followed up for nine years as a classical example of the lower oesophageal ring. The patient came to necropsy two years after a subtotal gastrectomy had been performed for a carcinoma of the antrum of the stomach. The oesophageal ring was found to be covered above by oesophageal mucosa and below by gastric glands.

More recently Barrett (1962) reviewed the problems presented by benign stricture in the lower oesophagus. He concentrated his discussion 
mostly on the topic of pathogenesis of the lesion after having treated 59 patients who had had benign oesophageal strictures due to reflux. Barrett resected six benign annular (or ring) strictures. He did not present complete data on these cases but he stated that in every one, histological preparations proved that there was, below the web, an oesophagus lined by columnar epithelium, a sliding hiatus hernia, or both'.

\section{CASE REPORT}

B. K., a man aged 28 years, entered the University Hospital of Uppsala on 17 September 1962 complaining of dysphagia since birth.

The patient had been a normal full-term baby. From the very beginning it was impossible for the child to be breast-fed. The baby regurgitated milk, aspirated it, and had attacks of cyanosis. The child was then fed with a teaspoon, and this seemed to be better tolerated. He slowly gained weight and was discharged from hospital four months after birth.

At home there was much difficulty in feeding, but dysphagia did not get worse when solid food was given, though it did persist during the following years. The child understood the necessity to eat slowly and to chew his food well; he knew that laughing or coughing during meals caused a painful 'sticking' sensation under the lower portion of the sternum. He was obliged immediately to drink some water or vomit in order to get relief.

Very frequent colds were also noticed. Radiographs of the chest were normal.

In October 1945, at the age of 11 years, the patient was admitted to the paediatric department of another hospital for further investigation of his dysphagia.

Radiographs of the oesophagus taken at that time showed slight enlargement of the intrathoracic portion with a narrowing at the level of the cardia. The lumen of the oesophagus was estimated to be one finger's breadth at a distance of about 1 in. $(25 \mathrm{~mm}$.) above the diaphragm; the mucosa appeared to be normal. Thick contrast passed down the oesophagus without difficulty.

Blood studies were within normal limits.

The diagnosis was cardiospasm. Since it was possible for the patient to swallow every kind of food, provided that he ate slowly and chewed it well, and since his weight was good, it was felt that there was no indication for surgery but that, should the dysphagia get worse, oesophageal dilatations should be tried.

Radiographs of the oesophagus taken in 1950 (at the age of 16) showed the same findings as previously. The oesophagus was abruptly narrowed one finger's breadth above the diaphragm. The contrast seemed to be mixed with food particles, but there was a passage to the stomach. No pathological changes were found in the lungs.
After doing his military service for a few weeks he was discharged from the Army, since he could not eat the food served.

The patient's symptoms continued throughout the following years without alteration. During sleep he was obliged to use at least two pillows under his head in order to avoid regurgitation. He denied heartburn or loss of weight.

A few months before admission he decided to undergo a complete physical re-examination, though his symptoms were still in statu quo.

On admission, physical examination was negative. He was a well-developed and well-nourished man. He was not ill.

Radiographs of the oesophagus showed a sharply demarcated circular constriction, as a ring-like band, two fingers' breadth above the cardia. Above the stricture the oesophagus was a little more than $3 \mathrm{~cm}$. in width. Below the stricture the oesophagus was normal and its contractions were normal (Fig. 1).

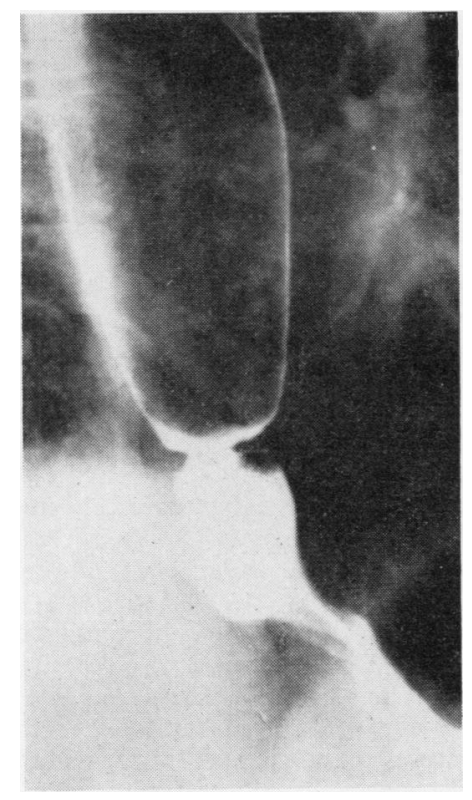

FIG. 1. Pre-operative radiograph demonstrating the lower oesophageal web and the dilated oesophagus.

The passage of the barium was retarded by the stricture. The radiological diagnosis was 'lower oesophageal web'.

Oesophagoscopy showed a dilated oesophagus with retention. The oesophagoscope passed into the stomach and no stricture was seen.

On 18 October 1962, at left thoracotomy, no abnormality could be seen or palpated until the oesophagus had been opened. A 3-cm. longitudinal incision was made at the predetermined site of obstruction. A web-like diaphragm covered on both 


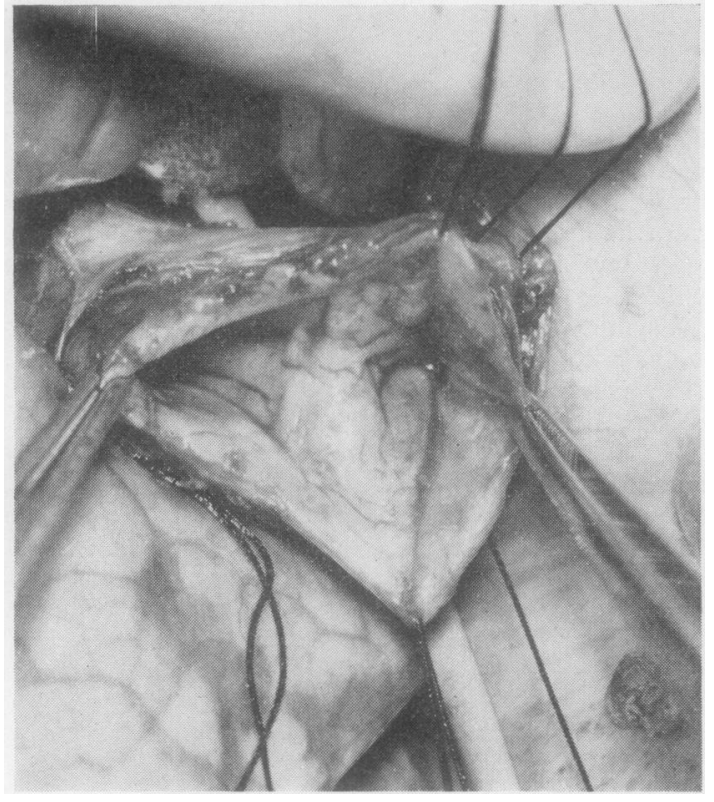

FIG. 2. The lesion seen at operation. A longitudinal incision was made at the predetermined site of the web.

sides by mucosa was seen (Fig. 2). The central opening was roughly estimated to be $1 \mathrm{~cm} .^{2}$ The oesophageal mucosa above and below the stricture appeared to be normal.

A circumferential excision of the stricture was performed and the edges of the resected stricture were re-approximated with 5-0 silk sutures. The oesophageal incision was closed transversely in two layers (mucosa and muscularis).

At operation the muscular coats appeared to be normal.

Histological examination of the removed specimen showed squamous-cell epithelium on both upper and lower surfaces of the web. There was squamous-cell hypertrophy and some hyperkeratosis on the superior surface. Many erosions were seen, mainly on the edges of the web. Chronic non-specific inflammatory changes with lymph follicles and an increased amount of collagen tissue (fibrous granulation tissue) were seen in the submucosa. Well-defined mucous glands and excretory ducts could be traced; these were normal. The submucosa was very vascular (Fig. 3).

The post-operative course was uneventful. A follow-up three and a half years after the operation showed that the patient had improved as regards his ability to swallow food. He had, however, to take a lot of fluid with meals. Regurgitation in the supine position persisted and during the night he had to use two to three pillows to avoid regurgitation. Radiographs showed that the oesophagus was dilated as previously (Fig. 4). The oesophagus could now dilate to a width of $1 \mathrm{~cm}$. in the region of the narrowing; an improvement in comparison with pre-operative pictures was found. The oesophagoscope could easily be passed through the narrowing. Three biopsies $1 \mathrm{~cm}$. below the narrowing demonstrated in one specimen a mucosa completely covered with squamous epithelium, in a second specimen both columnar and squamous epithelium was found, while in a third specimen the columnar epithelium dominated although a small part was covered with squamous epithelium of a metaplastic type. One centimetre below the narrowing the squamous cell mucosa predominated and beneath it there were fibrosis and chronic inflammatory changes (Fig. 5).

\section{DISCUSSION}

We shall confine our discussion to the welldocumented cases reported in the literature.

Unfortunately, today, five years after Bugden's statement (1957) that 'the amount of pathologic material available for study of this lesion was negligible', the situation is virtually unaltered.

Only one patient of Ingelfinger and Kramer (1953), one of Schatzki and Gary (1953), two of Bugden and Delmonico (1956), and one of MacMahon, Schatzki, and Gary (1958) came to surgery or to necropsy, plus the six patients operated upon by Barrett and mentioned in his lecture (1962), describing only the location and histological appearance of the rings.

As far as the symptomatology of these patients is concerned, dysphagia has been the main complaint. The dysphagia is usually described (Ingelfinger and Kramer, 1953) as a painful 'sticking' sensation sharply localized behind the lower portion of the sternum. The type and degree of dysphagia are usually consistent with the diameter of the ring (Schatzki and Gary, 1953). It seems that in all the patients a change in eating habits or a poorly masticated bolus can produce an acute obstructive episode.

The symptoms had usually been present for $\frac{D}{O}$ many years, but in none of the above records had the dysphagia been present since birth, as it was $N$ in our patient.

This is why none of the authors knew the cause of the disease-whether congenital or not-from the clinical history. Our patient's symptoms began immediately after birth, were always present up to the time of the operation ( 28 years), and an obstruction erroneously thought to be cardiospasm had already been diagnosed during childhood. The above history leads us to believe that the lesion in this patient was congenital.

None of the patients described in the literature had reflux of gastric secretions, heart-burn, or other symptoms of reflux. 


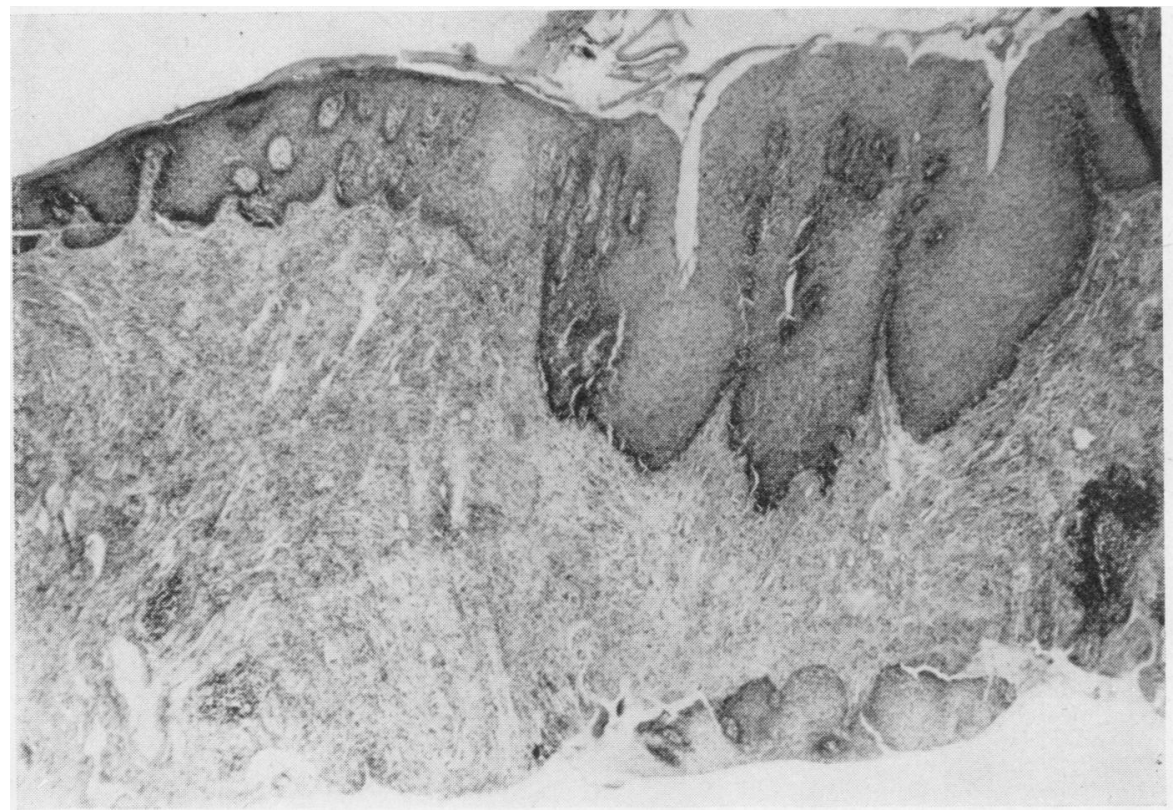

FIG. 3a. Photomicrograph of a cross-section of the lower oesophageal web shows hyperplastic squamous epithelium on both sides of the specimen $(\times 56)$.

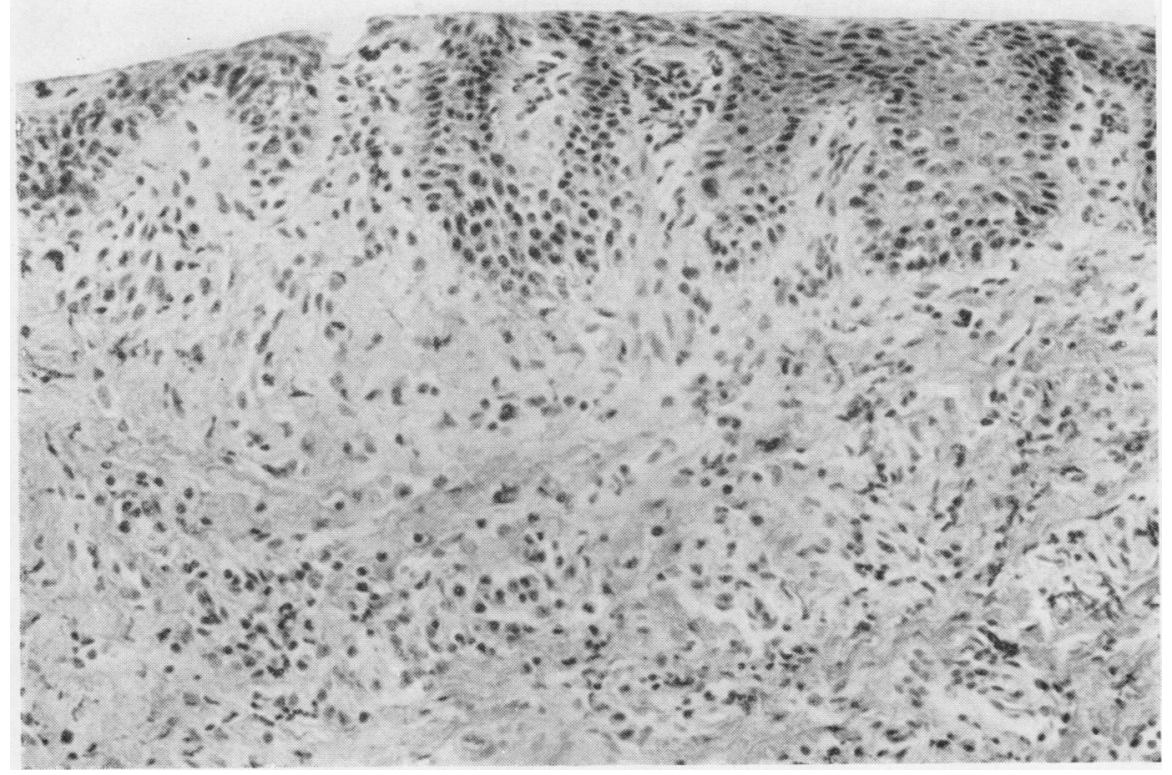

FIG. 3b. Photomicrograph showing a portion of the mucosa with atrophic epithelium, inflammatory changes, and fibrosis $(\times 220)$. 


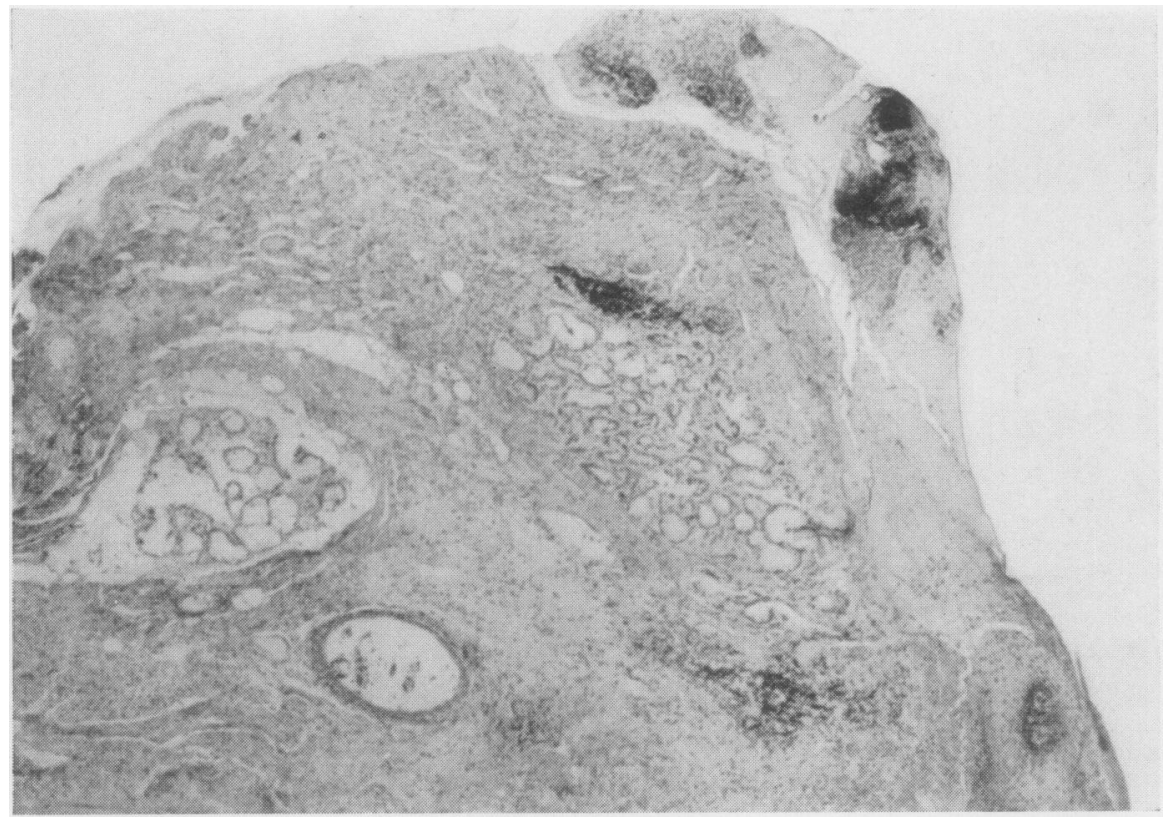

FIG. 3c. Photomicrograph showing numerous glands of the same type as are usually seen at the cardia below squamous epithelium $(\times 15)$.

The radiological appearance of the ring or web was comparable in all patients. The constriction consisted of a sharply demarcated negative shadow, a ring-like band 2 to $6 \mathrm{~mm}$. in width,

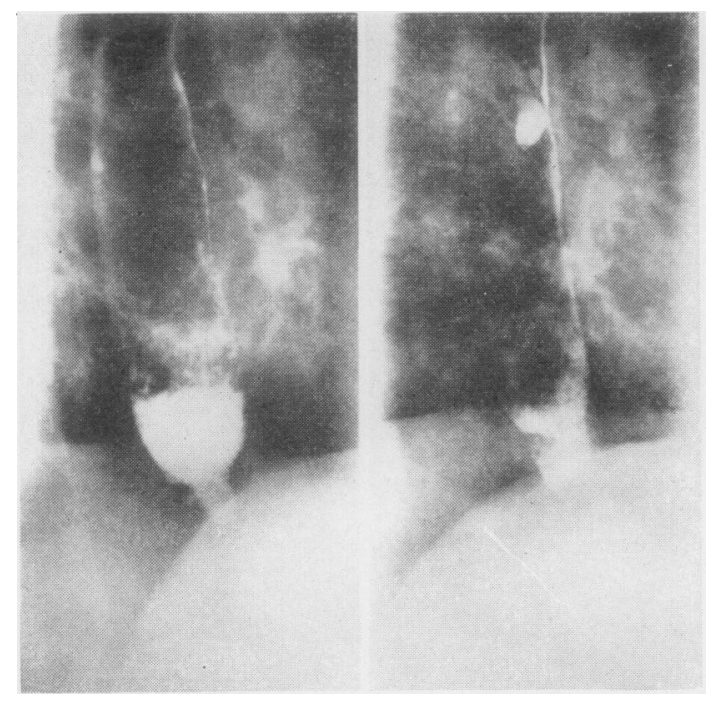

FIG. 4 (a and b). Post-operative radiographs showing the lower oesophagus improved but still narrowed, with considerable dilatation remaining above. which intersected the lumen at a right angle to the long axis of the oesophagus (Ingelfinger and $\overrightarrow{\hat{O}}$ Kramer, 1953). The web appeared always to be 3 2 to $5 \mathrm{~cm}$. above the diaphragm.

In most cases the web was not demonstrable until the oesophagus above and below it had been distended with a thick barium swallow.

Our radiologists had no difficulty in demon- $x$ strating the lesion, since our patient, having been apparently an air-swallower, distended his oeso phagus with air while swallowing the barium. The same effect can probably be produced by giving the patient bicarbonate powder during the barium? swallow.

Oesophageal peristalsis has been reported to be normal in these patients. The oesophagus aboven the narrowing is usually not widened. The short segment of the oesophagus distal to the ring is
also normal.

A diaphragmatic hernia was present in the case of Schatzki and Gary (1953), in that ofo MacMahon et al. (1958), and in all Barrett's casesD (1962).

The patient of Ingelfinger and Kramer (1953) had a duodenal ulcer, and a gastrectomy waso performed two years after the oesophageal resec -0 tion. None of the others discussed in this papero had a duodenal ulcer. Our patient did not have ao diaphragmatic hernia or duodenal ulcer. 


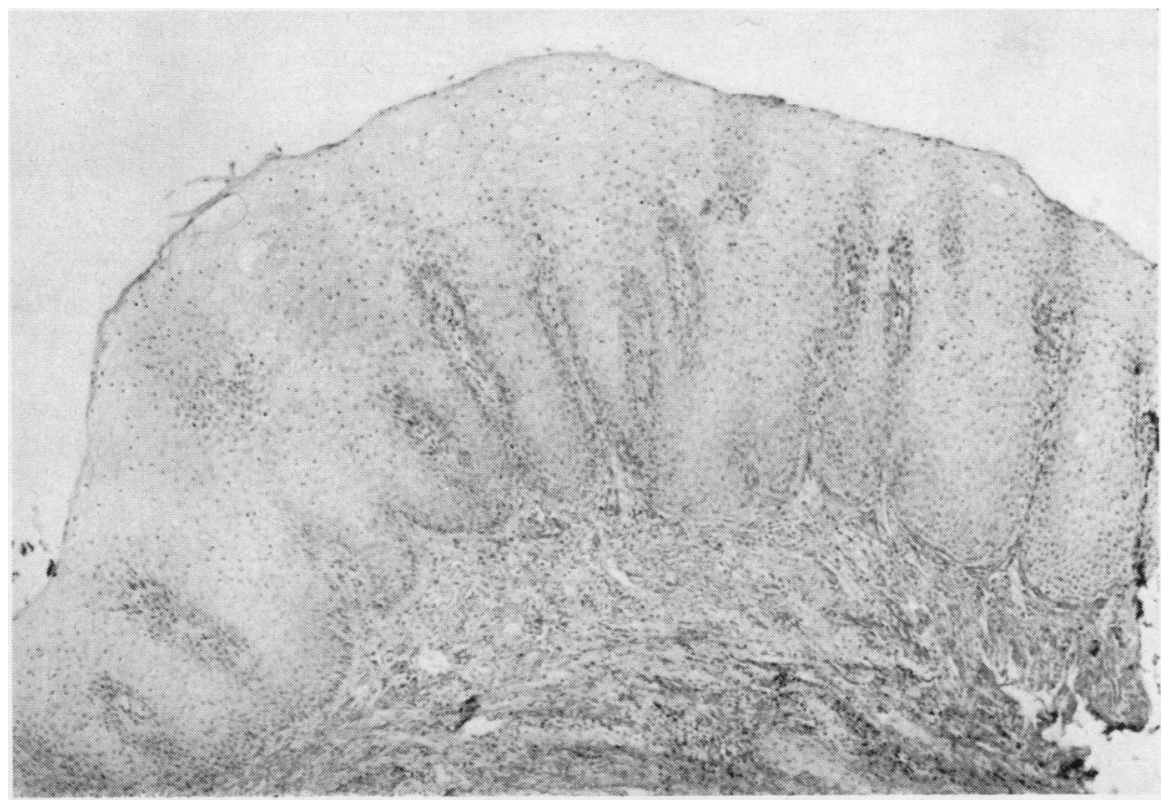

FIG. 5a. Photomicrograph of biopsy specimen taken $1 \mathrm{~cm}$. below the resected web, showing squamous cell epithelium.

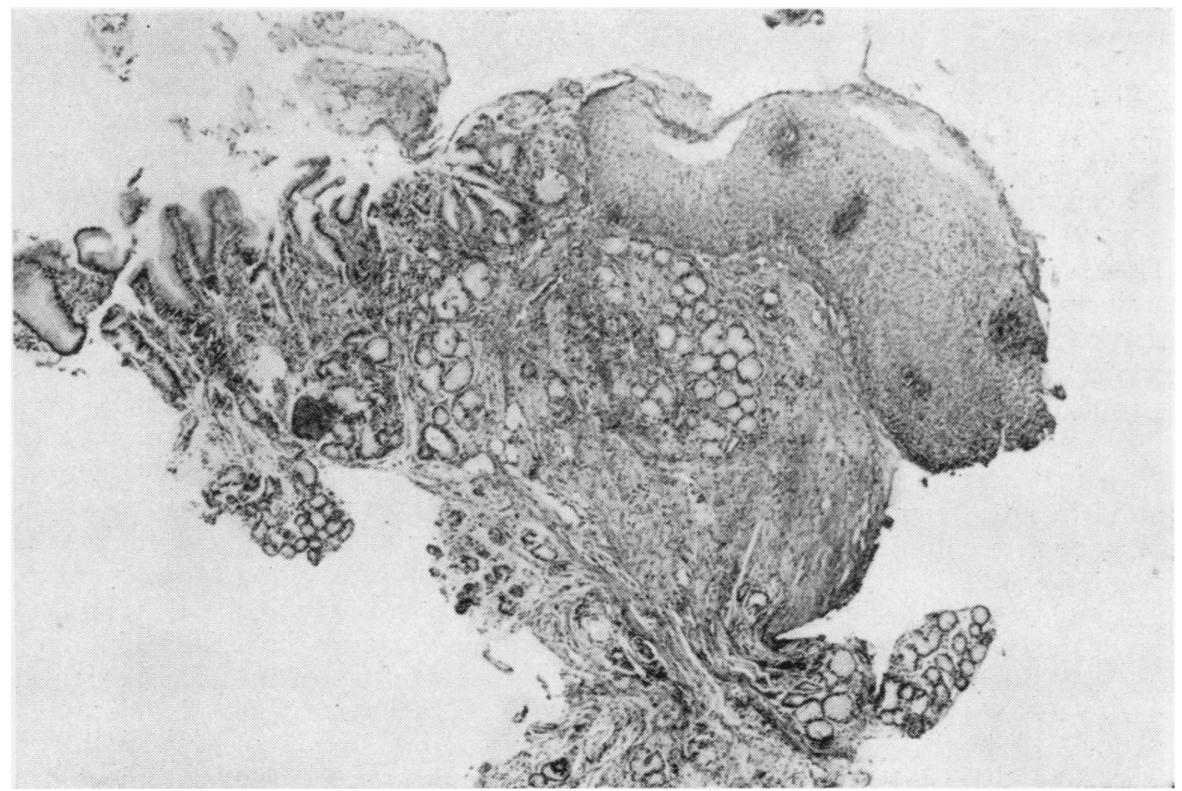

FIG. 5b. Photomicrograph of biopsy specimen taken $1 \mathrm{~cm}$. below the resected web, showing to the left columnar epithelium, to the right squamous cell epithelium. 


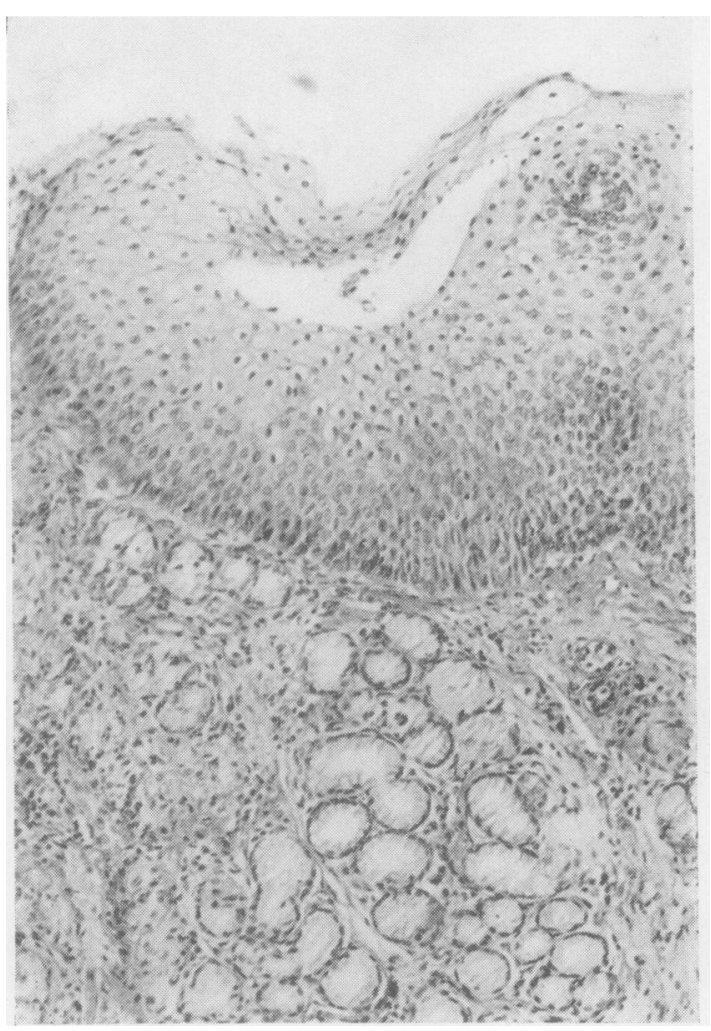

FIG. 5c. Enlargement of the photomicrograph shown in Fig. $5 b$.

In nearly all the patients the lesion was missed endoscopically. When one sees the lesion at operation or in a radiograph one wonders why it was missed at oesophagoscopy. As Bugden (1957) stated, 'endoscopy may lead to erroneous interpretations. The web may not be visualized as such and the examiner may be uncertain whether the oesophagogastric junction is difficult to pass or whether there is true organic obstruction'.

In the patient of Schatzki and Gary (1953) a $3 \mathrm{~mm}$. opening was seen. Delmonico (1956) mentioned a patient in whom the web was seen, and it was fractured in an attempt to pass the oesophagoscope through, resulting in complete relief of the patient's dysphagia.

At operation the lower oesophagus and the oesophagogastric junction appear usually normal to inspection and palpation. In one of Bugden and Delmonico's patients (1956) the lesion was palpable before the oesophagus was opened. It presented as a firm, circumferential thickening in the oesophageal wall. This area corresponded to the base of the web.
No patient had perioesophageal induration. $\stackrel{\overrightarrow{\bar{S}}}{\stackrel{\vec{S}}{+}}$ After the oesophagus has been opened, the lesion can easily be felt and seen.

Histological examination of the resected speci- $\frac{\bar{\omega}}{\vec{T}}$ men is of importance when discussing the patho- $\frac{\mathbb{Q}}{2}$ genesis of these webs or rings.

As has already been stated, the web can be $\rightarrow$ situated either above the oesophagogastric junc. tion, in which case both its surfaces are covered $\vec{\omega}$

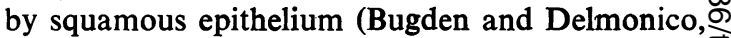
1956; our case; and probably Ingelfinger and $\vec{x}$ Kramer, 1953), or at the oesophagogastric junc-în tion, in which case the upper surface of the web ${ }_{N}^{N}$ is covered by oesophageal mucosa and the lower $-\vec{T}$ by gastric mucosa (Schatzki and Gary, 1953 ;G MacMahon et al., 1958 ; and Barrett, 1962). In the은 latter the oesophageal segment below the ring is presumably herniated stomach. In our patient the 3 squamous epithelium continued down to $1 \mathrm{~cm}$. below the narrowing, where an admixture with ${ }^{\text {? }}$ columnar epithelium was found.

With the exception of the patient of Ingelfinger. and Kramer (1953), the muscular layers of the oesophagus did not participate in the formation of the web or ring.

No evidence of inflammation was found in the patients of Ingelfinger and Kramer (1953), of Schatzki and Gary (1953), or of MacMahon et al. (1958). Chronic inflammatory cell infiltration of the submucosa was seen in the patients reported by Bugden and Delmonico (1956), by Barretto (1962), and in our case.

We are inclined to believe that continuous local $\overrightarrow{0}$ trauma can explain these findings.

The mucosa itself presented in almost all cases: some hyperkeratosis, but no ulceration or inflam matory changes were described.

Barrett (1962) stated recently that he believed 'these rings are the result of reflux oesophagitiso and they are the end result of inflammation in the mucosa and submucosa. They are caused by reflux oesophagitis that attacks the vulnerable squamous epithelium at the point where this changes to columnar epithelium. The stricture that forms in the submucosa may be above a slidingN hiatus hernia, alternatively it may be above ao lower oesophagus lined by columnar epithelium

We are strongly inclined to believe that this hypothesis cannot be applied in our case or ine? the case of Bugden and Delmonico (1956). (The case of Ingelfinger and Kramer (1953) will beo discussed later.)

Barrett's reason for stating that this is and acquired lesion and not congenital is the fact tha $f$ the epithelium below the orifice is columnar or 
'gastric'. 'If the deformity was congenital it is difficult to explain why the lining of the gullet should not be squamous on both sides of the obstruction' (Barrett, 1962).

Our patient has a clear-cut history of dysphagia since birth and fulfils also the above statement, since the mucosa above and below the stricture was oesophageal.

Would it then be wise to differentiate two different pathogeneses, one acquired and the other congenital, of a lesion which gives the same symptomatology and has somewhat similar macroscopic and microscopic appearances?

Barrett (1962), discussing the opinion expressed by Hayward (1961), who stated that if the lower oesophagus is lined by columnar epithelium, this is an acquired state because the patient had, at first, a sliding hiatus hernia that produced reflux and an oesophagitis, and that this destroyed the squamous epithelium above it for a greater or a lesser distance, the denuded area was re-epithelialized from columnar cells below ...., commented that 'it is difficult to imagine an inflammation so extensive that it denudes the epithelium from the lower 3 or 4 inches of the gullet and yet leaves so little trace in the submucosa of its existence later on.

'Second, it is unlikely that squamous epithelium would undergo metaplasia to columnar epithelium, and

'third, if the squamous epithelium is removed from the oesophagus of a dog, the raw surface is soon covered by squamous epithelium again'.

We like to retain these statements and simply say that thousands of patients have been operated upon for hiatal hernia of different sizes, severity of symptoms, and local pathological changes, and in none of them was a ring or web present. On the other hand, no patient with a web has been described as having any kind of oesophageal reflux in his past or present history, although we are aware of Barrett's statement (1962) that he has seen patients with stricture, without symptoms of oesophagitis, who had chronic inflammation and ulceration in the gullet.

It is difficult for us to accept the statement that 'the web stricture is a defense mechanism, or the end result that confines the spread of the disease (reflux oesophagitis) at the price of a moderate dysphagia that the patient can learn to live with' (Forssner, 1907). In studying the patients in whom this obstacle was removed surgically or broken endoscopically, it seems that this stricture was not necessary or even protective and that the patients did well without any complaints suggesting oesophageal reflux, etc.

It also seems that there is another type of web or ring in the lower oesophagus. There is only one unique, well-documented case in the literature, and that is the patient presented by Ingelfinger and Kramer (1953) who was operated upon; histological examination revealed only 'extremely thickened muscular wall. The mucosal lining of the lumen was oesophageal'. The authors have called this lesion a 'contractile ring of the lower oesophagus'. They were inclined also to place the site of the lesion above the true junction of the oesophagus and stomach and to identify the lesion as 'an overactive inferior oesophageal sphincter which represents a local muscular phenomenon which is present in many people but which is only rarely sufficiently pronounced to produce dysphagia'. Harris, Kelly, and Kramer (1960), after having studied 10 patients with dysphagia due to a lower oesophageal ring in an attempt to determine if the ring marked the functional oesophagogastric junction, concluded that 'the area distal to the lower oesophageal ring functions as oesophagus and that, regardless of its radiologic appearance, the ring does not invariably mark the oesophagogastric junction'.

Since the reported experiences with lower oesophageal webs have been very limited and the amount of pathological material available for study has been negligible (Bugden, 1957), it is very difficult to reach conclusions as to the pathogenesis of the lesion.

We feel that, at least with the present knowledge on the subject, we must differentiate between (1) congenital lower oesophageal web; (2) contractile lower oesophageal ring; and (3) short acquired lower oesophageal stricture.

This differentiation is similar to the classification of Findlay (1932) made 30 years ago, and to that of Bugden (1957).

\section{TREATMENT}

Although all the patients operated upon had a very pronounced dysphagia, it seems that most patients can survive without operation or dilatation simply by chewing their food well.

From some reported cases (Goldenberg and Smith, 1961 ; Delmonico, 1956) it seems that if the endoscopist is lucky he can cure the patient.

In the operating room the surgeon will decide which procedure to use (Bugden and Delmonico, 1956; Gross, 1948 ; Ingelfinger and Kramer, 
1953 ; Schatzki and Gary, 1953) and the local findings.

The procedure described by Bugden (1957) and Bugden and Delmonico (1956) is logical. They removed three pie-shaped wedges of membrane, leaving intervening areas of mucosa after exposing the lesion through a longitudinal incision on the oesophagus above and another one on the fundus of the stomach after opening the diaphragm. This procedure has been designed primarily to preserve the integrity of the oesophagogastric junction.

In our patient a small longitudinal incision was made in the oesophagus at the site of the web, the web was excised, the mucosal edges were reapproximated, and the edges of the longitudinal oesophageal incision were approximated in the transverse axis in two layers (oesophagoplasty) in order to avoid subsequent stenosis. This procedure was simple.

I wish to thank Professor Gösta Hultquist for the pathological investigation.

\section{REFERENCES}

Adams, R. (1956). Discussion on a paper of Bugden and Delmonico. J. thorac. Surg., 31, 16.

Barrett, N. R. (1962). Benign stricture in the lower esophagus. $J$. thorac. cardiovasc. Surg., 43, 703.

Beatty, C. C. (1928). Congenital stenosis of the oesophagus. Brit.J. Child. Dis., 25, 237.

Bugden, W. F. (1957). Lower esophageal web. Amer. J. Surg., 93, 248.

- and Delmonico, J. E., Jr. (1956). Lower esophageal web. $J$. thorac. Surg., 31, 1.

Delmonico, E. (1956). Closing discussion on a paper of Bugden and Delmonico. Ibid., 31, 18.
Evans, J. A. (1952). Sliding hiatus hernia. Amer. J. Roentgenol., 68 754. Quoted from MacMahon et al. (1958).

Findlay, L. (1932). Congenital stenosis of the oesophagus. Acta paediat. (Uppsala), 13, 70. Quoted from P. Sandblom (1948).

Forssner, H. (1907). Anat. Hefte, 34, 1. Quoted from P. Sandblom (1948).

Goldenberg, I. S., and Smith, H. (1961). Congenital esophageal web. Report of a case. J. thorac. cardiovasc. Surg., 41, 733.

Gross, R. E. (1948). Treatment of short stricture of the esophagus by partial esophagectomy and end-to-end esophageal reconstruction. Surgery, 23, 735 .

Guilleminet (1947). Oblitérations congénitales de l'oesophage par diaphragme membraneux. Lyon chir., 42, 210.

- and Lacour (1947). Atrésies et sténoses oesophagiennes congénitales par diaphragme membraneux. Pédiatrie, 36, 197.

Harris, L. D., Kelly, J. E., Jr., and Kramer, P. (1960). Relation of $\vec{x}$ the lower esophageal ring to the esophagogastric junction. i New Engl. J. Med., 263, 1232.

Hayward, J. (1961). The treatment of fibrous stricture of the oeso- iN phagus associated with hiatal hernia. Thorax, 16, 45. Quoted from Barrett (1962).

Ingelfinger, F. J., and Kramer, P. (1953). Dysphagia produced by a contractile ring in the lower esophagus. Gastroenterology, 23, $\mathrm{O}$ 419 .

Johnstone, A. S. (1951). The diagnosis of early gastric herniation at the oesophageal hiatus. J. Fac. Radiol. (Lond.), 3, 52. Quoted from MacMahon et al. (1958).

Jutras, A., Levrier, P., and Longtin, M. (1949). Étude radiologique de l'oesophage para-diaphragmatique et du cardia. $J$. Radiol. Électrol., 30, 373. Quoted from MacMahon et al. (1958).

MacMahon, H. E., Schatzki, R., and Gary, J. E. (1958). Pathology of a lower esophageal ring. New Engl. J. Med., 259, 1.

Macmillan, A. S. (1931). Diseases of the esophagus. Ibid., 204, 104. .

- (1935). Statistical study of diseases of the oesophagus. Surg. Gynec. Obstet., 60, 394.

Malenchini, M., and Resano, J. H. (1953). Serie de esofagopathias muy raras: observación No. 4: estenosis de esófago por doble membrana en diafragma iris (Web) congénito. Dia méd., 25, 1810.

Schatzki, R., and Gary, J. E. (1953). Dysphagia due to a diaphragm- (D) like localized narrowing in the lower esophagus ("lower esophageal ring"). Amer. J. Roentgenol., 70, 911.

Sweet, R. H. (1956). Discussion on a paper of Bugden and Delmonico. J. thorac. Surg., 31, 15.

Templeton, F.E.(1944). $X$-ray Examination of the Stomach: A Description of the Roentgenologic Anatomy, Physiology, and Pathologv of the Esophagus, Stomach, and Duodenum, pp. 106 and 112 . University of Chicago Press. Chicago. 